\title{
OPERATOR FUNCTIONS ASSOCIATED WITH THE GRAND FURUTA INEQUALITY
}

\author{
J. F. JiANG, E. KAMEI AND M. FuJII
}

\begin{abstract}
We discuss the monotonicity of operator functions associated with the grand Furuta inequality, some of which are considered under the chaotic order $\log A \geqslant \log B$. In some restricted cases, several known operator inequalities related to the Furuta inequality will appear as corollaries of our results.
\end{abstract} function.

Mathematics subject classification (1991): 47A30, 47A63, 47B15.

Key words and phrases: Positive operator, Furuta inequality, grand Furuta inequality and operator

\section{REFERENCES}

[1] T. ANDO AND F. HIAI, Log majorization and complementary Golden-Thompson type inequality, Linear Algebra Appl., 197 (1994), 113-131.

[2] M. FuJII, Furuta's inequality and its mean theoretic approach, J. Operator Theory, 23 (1990), 67-72.

[3] M. FUJII, T. FURUTA AND E. KAMEI, Operator functions associated with Furuta's inequality, Linear Algebra Appl., 149 (1991), 91-96.

[4] _ Furuta's inequality and its application to Ando's theorem, Linear Algebra Appl., 179 (1993), 161-169.

[5] Complements to the Furuta inequality, Proc. Japan Acad., 70 (1994), Ser. A ,239-242.

[6] Complements to the Furuta inequality, III, Math. Japon., 45 (1997), 25-32.

[7] M. FuJII, J.-F. JiAng AND E. KAMEI, Complements to the Furuta inequality, IV, Math. Japon., 45 (1997), 511-518.

[8] Characterization of chaotic order and its application to Furuta inequality, Proc. Amer. Math. Soc. 125 (1997), 3655-3658.

[9] Characterization of chaotic order and its application to Furuta's type operator inequalities, Linear Multilinear Alg., to appear.

[10] M. FUJII, J.-F. JIANG, E. KAMEI AND K. TANAHASHI, A characterization of chaotic order and a problem, J. Ineq. Appl., to appear.

[11] M. FUJII, J.-F. JiAnG AND E. KAMEI, A geometrical structure in the Furuta inequality, II, Nihonkai Math. J. 8 (1997), 37-46.

[12] M. FuJII AND E. KAMEI, A geometrical structure in the Furuta inequality, Math Japon., 43 (1996), 83-89; 389 (for Correction).

[13] Mean theoretic approach to the grand Furuta inequality, Proc. Amer. Math. Soc., 124 (1996), 2751-2756.

[14] T. FuRUTA, $A \geqslant B \geqslant 0$ assures $\left(B^{r} A^{p} B^{r}\right)^{1 / q} \geqslant B^{(p+2 r) / q}$ for $r \geqslant 0, p \geqslant 0, q \geqslant 1$ with $(1+2 r) q \geqslant p+2 r$, Proc. Amer. Math. Soc., 101 (1987), 85-88.

[15] _ A proof via operator means of an order preserving inequality, Linear Algebra Appl., 113 (1989), 129-130.

[16] Elementary proof of an order preserving inequality, Proc. Japan Acad., 65 (1989), 126.

[17] _ Two operator functions with monotone property, Proc. Amer. Math. Soc., 111 (1991), 511-516.

[18] _ Applications of order preserving operator inequalities, Operator Theory: Advances and Applications, 59 (1992), 180-190. 

Extension of the Furuta inequality and Ando-Hiai log-majorization, Linear Algebra Appl., 219 (1995), 139-155.

[20] , Parallelism related to the inequality " $A \geqslant B \geqslant 0$ ensures $\left(A^{\frac{r}{2}} A^{p} A^{\frac{r}{2}}\right)^{\frac{1+r}{p+r}} \geqslant\left(A^{\frac{r}{2}} B^{p} A^{\frac{r}{2}}\right)^{\frac{1+r}{p+r}}$ for $p \geqslant 1$ and $r \geqslant 0$ ", Math. Japon., 45 (1997), 203-209.

[21] E. HEINZ, Beiträge zur Störungstheorie der Spektralzerlegung, Math. Ann., 123 (1951), 415-438.

[22] J.-F. JIANG, E. KAMEI AND M. FUJII, The monotonicity of operator functions associated with the Furuta inequality, Math. Japon. 46 (1997), 337-343.

[23] E. KAMEI, A satellite to Furuta's inequality, Math. Japon., 33 (1988), 883-886.

[24] - Complements to the Furuta inequality, II, Math. Japon., 45 (1997), 15-23.

[25] F. KuBO AND T. ANDO, Means of positive linear operators, Math. Ann., 246 (1980), 205-224.

[26] K. LÖWNER, Über monotone Matrixfunktionen, Math. Z., 38 (1934), 177-216.

[27] K. TANahashi, Best possibility of the Furuta inequality, Proc. Amer. Math. Soc., 124 (1996), 141-146.

[28] _ The Furuta inequality in case of negative powers, RIMS, 903 (1995), 78-96.

[29] T. Yoshino, Introduction to Operator Theory, Pitman Research Notes in Math. Ser., 300, Longman Scientific and Technical, 1993. 